\title{
Evaluating the performance of the SIB system of health centers in Bojnourd and Neishabour from the perspective of users in 2020
}

\author{
Gholamreza Moradi ${ }^{1}$, Shadi Gholizade ${ }^{2}$, Reyhaneh Rostami ${ }^{2}$, Fateme Moghbeli ${ }^{3 *}$ (i) \\ ${ }^{1} \mathrm{PhD}$ in Health Information Management, Assistant Professor, Department of Health Information Technology, Varastegan Institute for Medical \\ Sciences, Mashhad, Iran \\ ${ }^{2}$ BS in Health Information Technology, Department of Health Information Technology, Varastegan Institute for Medical Sciences, Mashhad, Iran \\ ${ }^{3} \mathrm{PhD}$ in Medical Informatics, Assistant Professor, Department of Health Information Technology, Varastegan Institute for Medical Sciences, \\ Mashhad, Iran
}

Article Info
Article type:
Research

\section{Article History:}

Received: 2021-09-20

Accepted: 2021-12-20

Published: 2022-01-08

\section{* Corresponding author: \\ Fateme Moghbeli}

PhD in Medical Informatics, Assistant Professor, Department of Health Information Technology, Varastegan Institute for Medical Sciences, Mashhad, Iran

Email: moghbelif@varastegan.ac.ir
A B S T R A C T

Introduction: Nurses and medical staff and health technologists as the largest segment of the health system are the main users of health information systems that understanding the perspective and how to use this system can be effective in improving the quality of community health. The aim of this study was to evaluate the performance of the Sib system of health centers in Bojnourd and Neishabour.

Material and Methods: This is an applied study and was performed by descriptive cross-sectional method. The study population included all users of the Sib system in the health centers of Bojnourd and Neishabour who used the Sib system. Sampling was available and data were collected using a researcher-made questionnaire and data were analyzed using SPSS software version 21 .

Results: According to the findings of the study, the majority of users were $70 \%$ female and $30 \%$ male, $58 \%$ were in the age group of $30-39$ years, and $40 \%$ of them had $5-9$ years of work experience and also $63 \%$ of System users have a bachelor's degree. In the technical field, from the point of view of $40 \%$ of users, the ease of using the system is moderate.

Conclusion: Based on the identified factors, by strengthening the advantages of the system and also trying to eliminate or reduce the shortcomings in it, it is possible to institutionalize and use the system more practically in order to solve health problems.

\section{Cite this paper as:}

Moradi Gh, Gholizade S, Rostami R, Moghbeli F. Evaluating the performance of the SIB system of health centers in Bojnourd and Neishabour from the perspective of users in 2020. Front Health Inform. 2022; 11: 100. DOI: 10.30699/fhi.v11i1.333

\section{INTRODUCTION}

Information technology as a powerful tool is the most important factor in increasing the efficiency and effectiveness of organizations. Therefore, various industries have taken effective steps to use these technologies in order to maintain their survival in the current competitive environment and improve their consequences [1]. Therefore, systems must be implemented that can collect information and manage it [2]. Health information systems are coherent and integrated systems that are designed and set up to collect, record, process, retrieve and disseminate health information. Evaluation of health information systems is one of the ways to increase the reliability of the efficiency of these systems [ $\underline{3}$ ].

Therefore, evaluating the performance of these systems is very important [4]. Evaluating health information systems examines a wide range of information sources. These resources include patient data collection, storage, and retrieval systems, as well as systems for integrating, storing, and applying medical knowledge []].

In evaluating the information system, all human, technical and organizational aspects should be considered in the evaluations and the possibility of comprehensive evaluation of health systems should be provided []].

Developing countries, including Iran, are no exception to the developments related to the creation of electronic health records, and movements have been formed in our country's care system. For this purpose, the SIB system (integrated health system) 
was put into operation on February 2016.

SIB is the latest achievement of the Ministry of Health after designing several offline software, which is now among the projects implemented in this field can be considered the most complete and up-to-date system because in addition to being online, it can be implemented nationally and It has the integrity of the entered information. So far, the information of nearly 60 million Iranians has been entered in this system []]. Some of the goals of this system are: to implement the creation of electronic health records for the general public, creating a national database in the field of health, providing integrated health services to the Iranian public throughout the country, especially in low-income areas and suburbs in order to increase social justice and ensure the health of the people, improve the quality of health services through standards Establishing services in accordance with the latest national health programs, providing health services based on the specific needs of age groups, especially at-risk groups (mothers, children and the elderly), providing referral system in the health sector and providing services in the field of physicians Urban and rural families []․ Studies in the field of programs similar to the SIB system, such as the electronic health record, show that the use of such systems in today's complex health system faces challenges that require organizational context and training of human resources. Therefore, before implementation, technical and non-technical factors should be identified and implementation barriers should be removed [9].

The need to reduce the cost of care, improve the quality of care, the development of health services, as well as strategic considerations regarding the acquisition of competitive benefits, as a cornerstone of its benefits, justifies the development and use of such systems. On the other hand, due to the huge cost of purchasing and using hospital information systems, their incorrect choice can lead to their failure and cause a fatal blow to health centers [10].

Now, considering the important role of evaluating the performance of health information systems in improving patients' medical affairs and improving the quantity and quality of health services, the performance of the SIB system was examined.

\section{MATERIAL AND METHODS}

The present study is an applied study that was performed by descriptive cross-sectional method. The study place was Bojnourd and Neishabour. The study population consisted of 60 users of the SIB system in Bojnourd and Neishabour counties. Was in the plan. The research tool was a questionnaire and sampling was available.

The selection of indicators, which included five technical, professional, organizational, economic, ethical and legal fields, was collected based on similar studies and articles and under the supervision of experts in this field. Due to the fact that standard and citationable questionnaires were not obtained in this field. A researcher-made questionnaire with 31 questions and a 5-choice Likert scale was used to collect data.

The validity of the questionnaire was evaluated in several sessions with the help of expert panels consisting of experts in the Department of Health Information Technology of Varastegan Center for Higher Education of Medical Sciences and their expert opinions were applied and Cronbach's alpha was used to validate the questionnaire questions. Thus, five questionnaires were completed by users and in order to obtain Cronbach's alpha, SPSS software version 21 was used, which is an acceptable coefficient according to the obtained Cronbach's alpha coefficient $(0.745)$ and shows the reliability of the questionnaire questions.

After referring to the health centers of Bojnourd and Neishabour cities, 60 users of the system who had accepted to participate in the project were given a questionnaire and the purpose of the research and a general explanation about the questionnaire for the users of the SIB system in the centers referred by researchers were provided. . They were given the necessary assurance regarding the questionnaires and the confidentiality of the information, and then their informed consent was obtained. Finally, after completing the questionnaires by users, the collected data were entered into SPSS software and the necessary statistical analysis and description was performed on the software outputs.

\section{RESULTS}

According to the age classification table (Table 1), the majority of system users (58\%) were in the age group of 30 to 39 years.

Table 1: Age category of user companies

\begin{tabular}{|l|l|l|l|}
\hline Row & $\begin{array}{l}\text { Age Categories } \\
\text { (years) }\end{array}$ & Number & $\begin{array}{l}\text { Percent } \\
(\%)\end{array}$ \\
\hline 1 & $20-29$ & 13 & 22 \\
\hline 2 & $30-39$ & 35 & 58 \\
\hline 3 & $40-50$ & 12 & 20 \\
\hline 4 & More than 50 & 0 & 0 \\
\hline
\end{tabular}

According to Table 2, 40\% of users have 5 to 9 years of work experience and less than $17 \%$ of them have more than 15 years of work experience. Table 3 shows that gender was $70 \%$ female and $30 \%$ male. Table 4 shows that $63.33 \%$ of the system users had a bachelor's degree and $6.66 \%$ of them had a master's degree. 
Table 2: Frequency distribution of work experience

\begin{tabular}{|l|l|l|l|}
\hline Row & $\begin{array}{l}\text { Work Experience } \\
\text { (years) }\end{array}$ & Number & $\begin{array}{l}\text { Percent } \\
(\%)\end{array}$ \\
\hline 1 & $1-4$ & 12 & 20 \\
\hline 2 & $5-9$ & 24 & 40 \\
\hline 3 & $10-14$ & 14 & $23 / 23$ \\
\hline 4 & $15-19$ & 6 & 10 \\
\hline 5 & $20-24$ & 4 & $6 / 66$ \\
\hline 6 & More than 25 & 0 & 0 \\
\hline
\end{tabular}

Table 3: Frequency distribution of gender

\begin{tabular}{|l|l|l|l|}
\hline Row & Gender & Number & $\begin{array}{l}\text { Percent } \\
(\%)\end{array}$ \\
\hline 1 & Male & 18 & 30 \\
\hline 2 & Female & 42 & 70 \\
\hline
\end{tabular}

Table 4: Frequency distribution of education rate

\begin{tabular}{|l|l|l|l|}
\hline Row & Education & Number & $\begin{array}{l}\text { Percent } \\
(\%)\end{array}$ \\
\hline 1 & Associate Degree & 18 & 30 \\
\hline 2 & Bachelor & 38 & 63.33 \\
\hline 3 & Master & 4 & 6.66 \\
\hline
\end{tabular}

According to Table 5, the ability to solve unforeseen problems in the SIB system is at an average level and is equivalent to $50 \%$. Also, from the users' point of view, solving the unforeseen problems of the system has the lowest score and user satisfaction.

Table 6 shows that $43 \%$ of SIB system users have evaluated the system performance in terms of preventing the loss of files at a very high level. In total, $50 \%$ of users stated that in the professional field, the usability of the system at an average level and $50 \%$ of other users have evaluated it at very high and high levels.

According to Table 7, the system is moderate in terms of impact on responsibilities and increasing patient satisfaction and is equivalent to $46 \%$.

According to Table 8, the benefits obtained from the implementation of the system are high and equal to $43 \%$. Also, the system is at an average level in terms of impact on reducing forces and is equivalent to $43 \%$. Table 9 shows that the response rate of the system to legal needs is moderate and is equal to $56 \%$.

Table 5: System evaluation from the perspective of users in the technical field

\begin{tabular}{|l|l|l|l|l|l|l|}
\hline Row & Questions & $\begin{array}{l}\text { Very } \\
\text { much }\end{array}$ & Much & Medium & Low & $\begin{array}{l}\text { Very } \\
\text { Low }\end{array}$ \\
\hline 1 & $\begin{array}{l}\text { To what extent has the performance of the system } \\
\text { been tailored to your needs? }\end{array}$ & $16.66 \%$ & $20 \%$ & $46.66 \%$ & $13.33 \%$ & $3.33 \%$ \\
\hline 2 & $\begin{array}{l}\text { To what extent do you encounter unexpected } \\
\text { problems working with the system? }\end{array}$ & $10 \%$ & $26.66 \%$ & $30 \%$ & $26.66 \%$ & $6.66 \%$ \\
\hline 3 & $\begin{array}{l}\text { How simple is the ability to solve unforeseen } \\
\text { problems? }\end{array}$ & $0 \%$ & $6.66 \%$ & $50 \%$ & $40 \%$ & $3.33 \%$ \\
\hline 4 & How do you evaluate the ease of use of this system? & $6.66 \%$ & $3.33 \%$ & $40 \%$ & $20 \%$ & $0 \%$ \\
\hline 5 & Total & $8 \%$ & $22 \%$ & $42 \%$ & $25 \%$ & $3 \%$ \\
\hline
\end{tabular}

Table 6: System evaluation table from the perspective of users in the professional field (some questions)

\begin{tabular}{|l|l|l|l|l|l|l|}
\hline Row & Questions & $\begin{array}{l}\text { Very } \\
\text { much }\end{array}$ & Much & Medium & Low & $\begin{array}{l}\text { Very } \\
\text { Low }\end{array}$ \\
\hline 1 & $\begin{array}{l}\text { To what extent has the system had a positive } \\
\text { impact on the content and effectiveness of the } \\
\text { work? }\end{array}$ & $10 \%$ & $30 \%$ & $43.33 \%$ & $13.33 \%$ & $3.33 \%$ \\
\hline 2 & To what extent has the system changed tasks? & $23.33 \%$ & $26.66 \%$ & $40 \%$ & $10 \%$ & $0 \%$ \\
\hline 3 & $\begin{array}{l}\text { To what extent has the system changed } \\
\text { responsibilities? }\end{array}$ & $23.33 \%$ & $26.66 \%$ & $40 \%$ & $10 \%$ & $0 \%$ \\
\hline 4 & $\begin{array}{l}\text { To what extent has the system changed } \\
\text { current affairs? }\end{array}$ & $16.66 \%$ & $43.33 \%$ & $26.66 \%$ & $13.33 \%$ & $0 \%$ \\
\hline
\end{tabular}

Table 7: System evaluation table from the perspective of users in the organizational field (some questions)

\begin{tabular}{|l|l|l|l|l|l|l|}
\hline Row & Questions & $\begin{array}{l}\text { Very } \\
\text { much }\end{array}$ & Much & Medium & Low & $\begin{array}{l}\text { Very } \\
\text { Low }\end{array}$ \\
\hline 1 & How has the system affected communication? & $3.33 \%$ & $40 \%$ & $20 \%$ & 305 & $6.66 \%$ \\
\hline 2 & $\begin{array}{l}\text { How has the system affected the } \\
\text { responsibilities? }\end{array}$ & $13.33 \%$ & $20 \%$ & $46.66 \%$ & $20 \%$ & $0 \%$ \\
\hline 3 & $\begin{array}{l}\text { To what extent has the system increased } \\
\text { decision-making power? }\end{array}$ & $6.66 \%$ & $23.33 \%$ & $43.33 \%$ & $23.33 \%$ & $3.33 \%$ \\
\hline 4 & $\begin{array}{l}\text { To what extent has the system improved the } \\
\text { efficiency and effectiveness of the measures? }\end{array}$ & $6.66 \%$ & $36.66 \%$ & $40 \%$ & $16.66 \%$ & $0 \%$ \\
\hline
\end{tabular}


Table 8: System evaluation table from users' point of view in the economic field

\begin{tabular}{|l|l|l|l|l|l|l|}
\hline Row & Questions & $\begin{array}{l}\text { Very } \\
\text { much }\end{array}$ & Much & Medium & Low & $\begin{array}{l}\text { Very } \\
\text { Low }\end{array}$ \\
\hline 1 & $\begin{array}{l}\text { What are the general costs of the system in } \\
\text { your opinion? }\end{array}$ & $10 \%$ & $33.33 \%$ & $40 \%$ & $3.33 \%$ & $13.33 \%$ \\
\hline 2 & $\begin{array}{l}\text { How do you evaluate the benefits of } \\
\text { implementing the system? }\end{array}$ & $3.33 \%$ & $43.33 \%$ & $33.33 \%$ & $16.66 \%$ & $3.33 \%$ \\
\hline 3 & $\begin{array}{l}\text { Has the system been effective in reducing } \\
\text { forces? }\end{array}$ & $0 \%$ & $10 \%$ & $43.33 \%$ & $23.33 \%$ & $23.33 \%$ \\
\hline 4 & Total & $4 \%$ & $29 \%$ & $39 \%$ & $15 \%$ & $13 \%$ \\
\hline
\end{tabular}

Table 9: System evaluation table from the perspective of users in the field of ethics and law

\begin{tabular}{|l|l|l|l|l|l|l|}
\hline Row & Questions & $\begin{array}{l}\text { Very } \\
\text { much }\end{array}$ & Much & Medium & Low & Very Low \\
\hline 1 & $\begin{array}{l}\text { To what extent does the performance of the } \\
\text { system correspond to the existing legal } \\
\text { potentials? }\end{array}$ & $0 \%$ & $10 \%$ & $66.66 \%$ & $20 \%$ & $3.33 \%$ \\
\hline $\begin{array}{l}\text { To what extent does the system meet the legal } \\
\text { needs of the organization? }\end{array}$ & $0 \%$ & $20 \%$ & $56.66 \%$ & $23.33 \%$ & $0 \%$ \\
\hline $\begin{array}{l}\text { To what extent has the system improved the } \\
\text { identification and access to clients? }\end{array}$ & $10 \%$ & $26.66 \%$ & $43.33 \%$ & $16.66 \%$ & $3.33 \%$ \\
\hline 4 & $\begin{array}{l}\text { To what extent has the system secured patient } \\
\text { data? }\end{array}$ & $23.23 \%$ & $40 \%$ & $23.23 \%$ & $10 \%$ & $3.33 \%$ \\
\hline 5 & $\begin{array}{l}\text { How correctly are the access levels of people } \\
\text { in the system classified? }\end{array}$ & $3.33 \%$ & $40 \%$ & $50 \%$ & $6.66 \%$ & $0 \%$ \\
\hline 6 & Total & $7 \%$ & $27 \%$ & $48 \%$ & $16 \%$ & $2 \%$ \\
\hline
\end{tabular}

\section{DISCUSSION}

Evaluation can be considered as one of the most important pillars of management of any system that measures the performance of a system in achieving the specific goals of that system. Like all information systems, the evaluation of the SIB system is necessary to improve and enhance the quality of the system. The present study evaluates the performance of the SIB system in five areas: technical, professional, organizational, economic, and ethics and law.

In the technical field, 4 questions were provided to users, which according to the scores obtained from summarizing the users 'views, the system performance is $46 \%$ in line with users' needs, as well as the ability to solve unforeseen problems is $50 \%$ simple and easy to use The system was $40 \%$, all of which were evaluated at an average level.

According to Table 6, the evaluation of the system from the perspective of users in the technical field, on average, $8 \%$ of users are very high, $22 \%$ of users are high, $42 \%$ of users are moderate, $25 \%$ of users are low and $3 \%$ of users in They have rated the system very low. The highest frequency and satisfaction in the technical field of the system have been evaluated by $42 \%$ of the average and $25 \%$ of the users in the low level of the system, which is not a good sign of the technical field of the system and this system needs to be reviewed and corrected; Only 30\% of users have had good satisfaction with the technical field of the system, which is not significant.

Another problem is the lack of user feedback to design the system. When users are not sufficiently involved in the design of the project, user interaction may seem irrational to them or, for example, the performance routine recommended by the system may be contrary to the usual applications of users [11].

In the professional field, 12 questions were provided to the users. According to the scores obtained from summarizing the users 'point of view, the system has a $43 \%$ positive effect on the content and effectiveness of the work and has changed the users' tasks, both of which are average scores. Have earned. $50 \%$ of users believe that working with this system saves time on average. In general, $40 \%$ of users were satisfied with working with the system and 50\% rated the usability of the system as useful at a moderate level.

In the system evaluation table in the professional field, on average, $17 \%$ of the system users in the professional field have evaluated very high, $27 \%$ high, $38 \%$ moderate, $12 \%$ low and $6 \%$ very low. The highest frequency of users' views in the professional field of the system was equal to $38 \%$ and was moderate, and only $44 \%$ of users in the system were very satisfied, which according to the above values and percentages, need to be reviewed and corrected in this area.

In the study of Ebadifar et al., Which was conducted with the aim of examining users' opinions about the 
computer information system of hospital information in Tehran hospitals, observing the principle of userfriendliness was declared the most effective factor in the satisfaction of system users [12].

In the study of Moghaddasi et al., Which examines the studies conducted on hospital information systems in Iran, improving the quality of health services, improving the economics of treatment and reforming policies in the health sector are among the benefits expressed about these systems [13].

In the study of Jabraili et al., The most benefits of implementing a hospital information system are improving the quality of health services and timely access to information [14].

According to a study by Damari et al., One of the problems with the health record system is that it takes time to complete due to the multiplicity of activities, and more than three-quarters of the participants agreed that completing the health record is very time consuming [15].

In the organizational field, 11 questions were provided to users, which according to the scores obtained from summarizing the views of users, $46 \%$ of users have evaluated the impact of the system on responsibilities at a moderate level. 33\% of users rated the impact of the system on improving communication between physician and patient at a moderate level. $40 \%$ of users believe that the system has acted moderately in reducing the waiting time for patients to receive services. Also, from the perspective of $46 \%$ of users, the system has acted moderately in terms of increasing patient satisfaction.

On average, the results obtained from this table show that system users in the organizational field have evaluated $6 \%$ as very high, $24 \%$ as high, $39 \%$ as medium, $22 \%$ as low and $9 \%$ as very low. . The highest frequency is $39 \%$ on average and only $30 \%$ of users are satisfied with the performance of the system in the organizational field. $30 \%$ of the desired satisfaction is a small percentage and indicates that the system in the organizational field also needs to be reviewed and reformed to improve the system in the eyes of users.

In a study conducted by Tucker and Davis to examine the knowledge and attitudes of clinical staff and IT managers toward hospital information systems, message exchange within the organization and appropriate communication between providers, improving the quality of care and improving the workflow, as well as better efficiency and time management for care providers [14].

One of the points mentioned by the users was the lack of proper attention and response to the criticisms related to the system by the top managers. This negligence led to user dissatisfaction, which could ultimately lead to a reduction in the efficiency and effectiveness of the SIB system [12].

In the economic field, 3 questions were provided to the users, which according to the scores obtained from summarizing the users' point of view, $40 \%$ of the users consider the total costs of the system at the average level and $43 \%$ of the users the benefits obtained from the system at the level Highly evaluated. Also, $43 \%$ of users believe that the system has acted moderately in reducing costs.

On average, user satisfaction in the economic field is estimated at $4 \%$ very high, $29 \%$ high, 39\% medium, $14 \%$ low and $14 \%$ very low. The highest frequency in the economic field of the system is $39 \%$ on average and only $34 \%$ of users have expressed their satisfaction with the performance of the system in the economic field, which is not very appropriate and it is recommended to review and modify the system in this area.

In a study examining the opinions of users of hospital information systems in Tehran, Ebadifar et al. stated some of the benefits of these systems as follows: eliminating the traditional system and paper workflow, reducing waste of hospital resources and reducing costs [12].

In the field of ethics and law, 5 questions were provided to users, which according to the scores obtained from summarizing the users' point of view, from the point of view of $66 \%$ of users, the system performance was in terms of compliance with existing legal potentials at the intermediate level.

Also, $56 \%$ of users rated the system's response to legal needs as moderate. $40 \%$ of users of this system believe that it causes a high level of patient data security. $50 \%$ of users also rated the level of access levels of people in the system as moderate.

The results obtained from the table show that on average $7 \%$ of users are very high, $27 \%$ of users are high, $48 \%$ of users are medium, $16 \%$ of users are low and $2 \%$ are very low of system performance in the field. Ethics and law were satisfied. The highest frequency averaged $48 \%$ on average and only $34 \%$ of users had good satisfaction with the performance of this system, and this indicates the weakness of the system in the field of ethics and law and it is necessary to review and reform the system in this area.

In a study entitled Patients' Attitudes towards Access to Electronic Health Records in Primary Care, maintaining security and privacy has been one of the most important concerns of patients [16]. Disruption requires proper legal infrastructure. The lack of binding laws for the faster development of e-health in the country and laws that make e-health one of the main priorities is one of the existing gaps [17]. The 
study of Farzandipour et al. Shows that Iran does not have comprehensive requirements for Information security is an electronic health record, and the design and formulation of electronic health record safety requirements is effective using the experiences of successful countries in this regard [18].

\section{CONCLUSION}

According to the views and results obtained from the performance evaluation tables of the SIB system, which were conducted by its users in five areas: technical, professional, organizational, economic, ethics and law. On average, the majority of users evaluated the SIB system as moderate. Since this system is a national and comprehensive system and is to be implemented in all health centers and replace the manual files of households, it is necessary to review and make the necessary corrections in all areas to improve it. To satisfy the users, the necessary measures should be taken and by strengthening its advantages as well as trying to reduce or eliminate the shortcomings and defects in the system, it should be institutionalized and used more practically in order to solve health problems. Limitations of the study include travel restrictions due to coronary conditions, lack of cooperation from health center staff to fill out questionnaires.

\section{ACKNOWLEDGMENTS}

Varastegan Institute for Medical Sciences is appreciated and thanked for its spiritual support.

This article is the result of a research project entitled Assessing the performance of the SIB system of health centers in Bojnourd and Neishabour from the perspective of users in 2020, approved by Mashhad University of Medical Sciences, in 1400 Ethics code number IR.MUMS.REC.1400.107 Obtained from the National Ethics Committee in Biomedical Research.

\section{AUTHOR'S CONTRIBUTION}

All authors contributed to the literature review, design, data collection and analysis, drafting the manuscript, read and approved the final manuscript.

\section{CONFLICTS OF INTEREST}

The authors declare no conflicts of interest regarding the publication of this study.

\section{FINANCIAL DISCLOSURE}

No financial interests related to the material of this manuscript have been declared.

\section{REFERENCES}

1. Ghazi Saeedi M, Safdari R, Sharifian R, Mohammadzadeh N. Evaluation of hospital information systems (HIS) in general hospitals of Tehran university of medical sciences: Perspective of physician and nurses. Payavard. 2014; 7(5): 447-56.

2. Amiresmaili M, Zarei L, Sheibani E, Arabpur A. Evaluation of the indicators of hospital information system. Health Information Management. 2013; 10(1): 1-13.

3. World Health Organization. Developing health management information systems: A practical guide for developing countries. WHO Regional Office for the Western Pacific; 2004.

4. Ammenwerth E, Brender J, Nykanen P, Prokosch H-U, Rigby M, Talmon J, et al. Visions and strategies to improve evaluation of health information systemsreflections and lessons based on the HIS-EVAL workshop in Innsbruck. Int J Med Inform. 2004; 73(6): 479-91. PMID: 15171977 DOI: 10.1016/j.ijmedinf.2004.04.004 [PubMed]

5. Friedman CP, Wyatt JC, Shortliffe EH, Smith AC, Kaplan B. Evaluation methods in medical informatics. New York, Springer; 2000.

6. Rahimi B, Vimarlund V. Methods to evaluate health information systems in healthcare settings: A literature review. J Med Syst. 2007; 31(5): 397-432. PMID: 17918694 DOI: 10.1007/s10916-007-9082-z [PubMed]
7. Introduction of Integrated Health System (Launch, Objectives, Features [Internet]. 2017 [cited: 5 May 2019]. Available from: http://www.iribnews.ir/fa/news/1673949

8. Jafari H, Ranjbar M, Amini-Rarani M, Hashemi FS, Bidoki SS. Experiences and views of users about delivering services through the integrated health system: A qualitative study. The Journal of Toloo-eBehdasht. 2020; 19(2): 57-71.

9. Morton ME, Wiedenbeck S. A framework for predicting EHR adoption attitudes: A physician survey. Perspect Health Inf Manag. 2009; 6(16): 1a. PMID: 20169013 [ PubMed]

10. Shayan M. Success assessment hospital information system (HIS) to the purpose improvement satisfaction of system users in hospitals. Safire Salamat. 2016; 6(13): 54-67.

11. Naghibzadeh GH, Safari Mohammadi F. Solutions for improving the health integrated system based on the experiences: A qualitative study. Congress of Information Technology and Health Promotion. 2018.

12. Ebadi Fard Azar F, Ansari H, Zohour A, Marashi S. Users' comments on computer information system of hospital information in Tehran hospitals. Petition Quarterly. 2006; 1(6): 11-18.

13. Moghaddasi H, Asadi F, Hosseini A, Mohammadpur A. Hospital information system: Findings from a systematic literature review. Hakim Research Journal. 2013; 16(3): 228-35

14. Jabrailly M, Rahimi B, Zare Fazl Allahi Z, Dolani A. The 
advantages and disadvantages of implementation of hospital information systems in educational centers of Urmia university of medical sciences. Monthly Journal of Urmia Nursing and Midwifery Faculty. 2012; 10(3): 326-31.

15. Kabir M, Ashrafian Amiri H, Rabiei S, Keshavarz A, Hosseini S, Nasrollahpour Shirvani SD. Satisfaction of family physicians and health care providers in Fars province and Mazandaran province from integrated health system. Journal of Health and Biomedical Informatics. 2017; 4(4): 244-52.

16. Tavakoli N, Saghayan Nejad Isfahani S, Piri Z, Mirzaeen R, Amini A. A comparative study of the laws, policies and procedures for the patient's access to the electronic health record in Australia, Canada and New Zealand compared to Iran. Journal of Shahrekord University of Medical Sciences. 2013; 15: 1-11.

17. Zare Beidaki M, Sadrinia S, Rajab Pour A. Evaluating electronic learning management systems at Iran medical sciences universities and several advanced countries. Strides in Development of Medical Education. 2015; 12(1): 18-27.

18. Nagipour $M$, Ahmadi $M$. Evaluating the strategic planning of electronic health and reviewing the barriers and challenges in Iran. Journal of Islamic Azad University of Medical Sciences. 2017; 27(4): 237-43. 